\title{
POWER TRACTION AND SUSPENSION SYSTEM OF MAGLEV TRAIN
}

\author{
Cao Junci ${ }^{1}$, Li Weili ${ }^{1}$, Wu Zhigang ${ }^{1}$, Yang Shaohua ${ }^{2}$ \\ ${ }^{1-}$ School of Electrical Engineering, Beijing Jiaotong \\ University, Beijing, 100044, China \\ 2-Jiang Su Weiteli Motor Limited By Share Ltd, Taizhou \\ 225318, China
}

\section{Introduction}

Maglev train has the advantages of low energy consumption, low noise, strong climbing ability, high operation speed, large acceleration space and more comfortable than wheel rail train. And in China, the distance between cities is different from Japan and other countries. Under such conditions only the maglev train has the advantage of competing with the aircraft.

Since 2002, the world's first commercial maglev train line operators started running in Shanghai. By 2016, China's first commercial operation in low speed maglev demonstration line which has completely independent property rights - Changsha Maglev Express Start running.

\section{Power Traction and Suspension Systems}

2.1 Electro Magnetic Suspension

As shown in

Fig. 1, the suspension principle and drive of long stator for EMS is based on the attractiveness of regular conductors magnet and ferromagnetic long stator rail. The electromagnet is dynamically 
adjusted by the air gap sensor and the acceleration sensor so that the air gap can be maintained at $8 \mathrm{~mm}$ and $12 \mathrm{~mm}$ in accordance with the operating speed to ensure safe life characteristics.

\subsection{Electro Dynamic Suspension}

As shown in Fig. 2, EDS is based on the principle of electromagnetism magnetic levitation. The superconducting magnet coils are laterally mounted at the end of each unit and at the transition, and induced eddy currents in the track coil. The train can suspension when increase to a certain speed. The height of the suspended air gap is between $100 \mathrm{~mm}$ and $150 \mathrm{~mm}$, and the adjustment device can be omitted. Since the principle of magnetic flux leakage is large, we need to shield passengers.

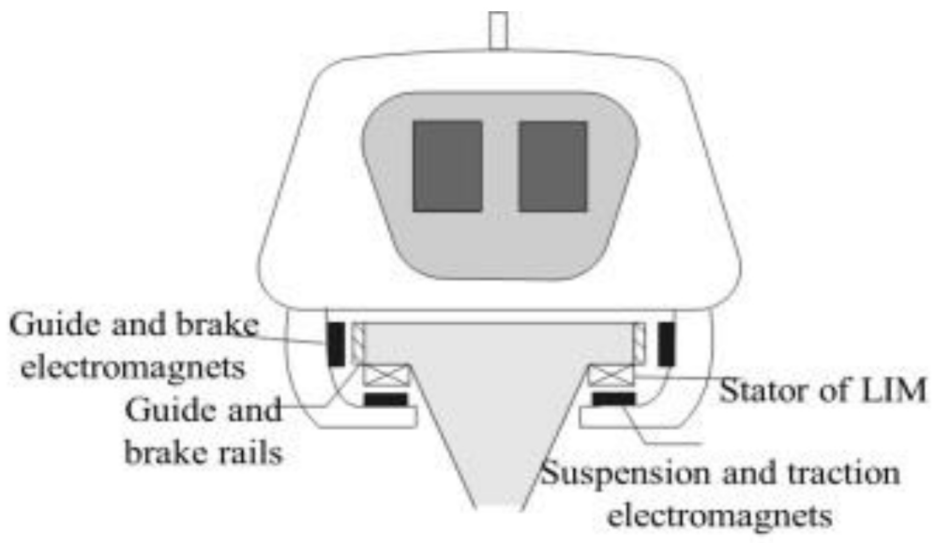

Fig. 1. EMS 


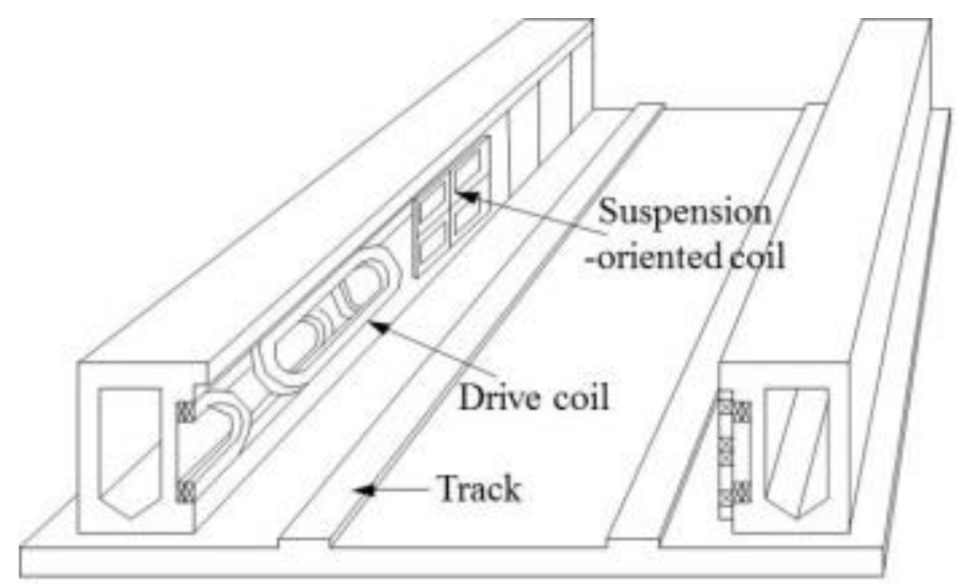

Fig. 2. EDS

III. Comparison of Two Electromagnetic Systems

EMS covers a large range of operation, in smaller traffic and lower speed can also be used economically. It's economic only the traffic volume is very large for Japan's EDS because of the high investment. Table 1 compares the differences between the two systems.

Table 1. Differences Between the Two Systems

\begin{tabular}{ccc}
\hline & \multicolumn{1}{c}{ EMS } & EDS \\
\cline { 2 - 3 } Design & Adjustable electromagnet & $\begin{array}{c}\text { Superconducting } \\
\text { magnets }\end{array}$ \\
\cline { 2 - 3 } Princi & The closed-loop control of & The coupling of support, \\
ples & support, guidance and drive & guidance and drive \\
\hline
\end{tabular}




\begin{tabular}{ccc}
\hline & are decoupled. & $\begin{array}{c}\text { requires additional } \\
\text { stabilization measures. }\end{array}$ \\
\cline { 2 - 3 } & $\begin{array}{c}\text { The guide and support } \\
\text { systems are arranged } \\
\text { separately in the rails. }\end{array}$ & Side wall suspension. \\
\hline Track & $\mathrm{T}$ & $\mathrm{U}$ \\
\hline vehicle & Outer riding on the rails & Buckle on the rails. \\
\hline EMER & The magnet can fall on the & Designed by the aircraft \\
& sled. & standard wheel. \\
\hline \multirow{3}{*}{ Drive } & synchrotron long linear & synchrotron long linear \\
power & Supply voltage: $0 \mathrm{kV} \sim 15$ & motor with no yoke; \\
supply & $\mathrm{kV}, 1200 \mathrm{~A}$, & $22 \mathrm{kV}, 1000 \mathrm{~A}$, \\
& $0 \mathrm{~Hz} \sim 250 \mathrm{H}$ & $0 \mathrm{~Hz} \sim 56 \mathrm{~Hz}$ \\
\hline
\end{tabular}

\section{Information about authors:}

Cao Junci, School of Electrical Engineering, Beijing Jiaotong University, Beijing, 100044, China

Li Weili, School of Electrical Engineering, Beijing Jiaotong University, Beijing, 100044, China

E-mail: li.weili@yeah.net

Wu Zhigang, School of Electrical Engineering, Beijing Jiaotong University, Beijing, 100044, China

Yang Shaohua, Jiang Su Weiteli Motor Limited By Share ltd, Taizhou 225318, China 